\title{
THE EDUCATIONAL EXPERIENCE AT POLITECNICO DI TORINO TO DEVELOP AND INCREASE THE CAPABILITY IN AIRCRAFT LAYOUT COMPREHENSION AND DEFINITION
}

\author{
Sergio CHIESA ${ }^{1}$, Marco FIORITI ${ }^{2}$, Roberta FUSARO ${ }^{3}$ \\ Department of Mechanical and Aerospace Engineering, Politecnico, c.so Duca degli Abruzzi 24, \\ 10129 Torino, Italy \\ E-mails: ${ }^{1}$ sergio.chiesa@polito.it; ${ }^{2}$ marco.fioriti@polito.it (corresponding author); ${ }^{3}$ roberta.fusaro@polito.it
}

Received 24 September 2014; accepted 24 February 2016

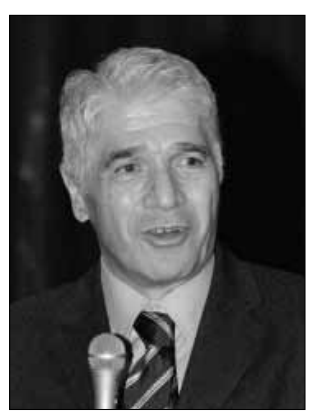

Sergio CHIESA was born in 1948 and got the degree in Aeronautical Engineering at Politecnico di Torino in 1972. After being involved in the Tornado Program, in 1976, he was enrolled in Politecnico di Torino as Assistant of Aeronautical Design and since 1990 he was full professor in the Mechanical and Aerospace Department. He worked in the Aerospace Systems Engineering research group of the same Department and was involved in many Italian and international projects. He is the author of many technical papers about aircraft systems, aircraft design and reliability and logistic Support.

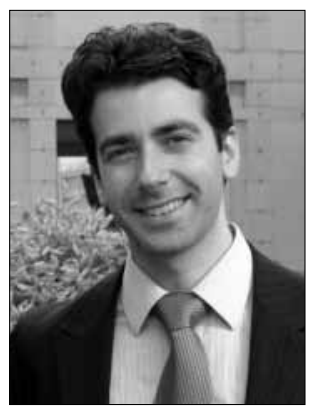

Marco FIORITI was born in 1980 in Turin and got his Master's Degree in Aerospace Engineering in 2006 at Politecnico di Torino. He carried out his research in collaboration with the Preliminary Design Office of Leonardo Aircraft Division (formerly Alenia Aermacchi) and he got his PhD in 2010. Since 2010 he has worked in Aerospace Systems Engineering research group within the Mechanical and Aerospace Department of Politecnico di Torino. He is the co-author of many scientific publications about the conceptual and preliminary design of aircraft, on-board system design, more electric aircraft, hybrid propulsion, RAMS and LCC.

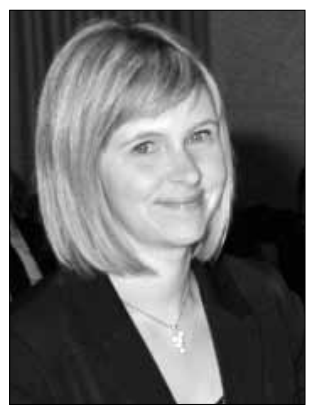

Roberta FUSARO was born in 1989 in Turin and she enrolled at Politecnico di Torino in 2008 and she completed her Engineering studies in 2013 when she received her MSc Degree. In October 2013, she started her collaboration with the Aerospace Systems Engineering Research Group, in the Mechanical and Aerospace Department of Politecnico di Torino, and, since January 2014, she has attended the PhD course in Aerospace Engineering. She contributed, as co-author, to some scientific articles and congress proceedings and her research is focused on aircraft conceptual design, hybrid propulsion, simulation methodologies, technological roadmaps and hypersonic transportation systems.

\footnotetext{
Abstract. The aim of this paper is to present the recent experience in the education of Aircraft Engineers of a very peculiar aspect, the Airplane lay-out definition, in order to provide students at first with a global vision of the plane, the capability to operate in lay-out definition and to be conscious of such a context, clearly interfaced with all other design activities. At first, it is discussed how relevant and essential Aircraft Design Education is in a wider Aircraft Engineering Education context. Then it is described how Design is comprehensive for both Quantitative and Qualitative definitions, pointing out that Qualitative definitions, like an Airplane Layout (at a Subsystems level of the "block scheme" too), are extremely relevant but very difficult to acquire. So, an idea to start to educate young Engineers (PhD Students in particular) has been developed and, for the first time, has recently been held at our Politecnico. The organisation and the program of the course are described, with detailed attention to peculiar topics or practical exercises considered to be
} 
particularly useful to reach the educational objectives. In such a way a sort of logical guideline to starting to sketch an initial layout is acquired by the students. It is relevant how the undeniable interest generated by historic airplanes can be a powerful means to push Students to try to understand architectures and, eventually, to elaborate new solutions.

Keywords: engineering education, aircraft design, aircraft architecture evolution, aircraft drawing layout.

\section{Introduction}

Politecnico di Torino aims to be an Excellent Technical University in the field of Research, Technological Transfer and Education; it is clear that these three aspects are synergic and only through their global progress it is possible to think of a future of progression and prosperity, especially considering the complex present situation.

Education has a basic relevance considering how the two other fields, as well as the daily progress of Industrial Activities, will only proceed efficiently according to the quality level of future engineers.

This fact, obvious for the 2 lower levels of education (Bachelor and Master's degree following the "Bologna process"), becomes even more important for the higher level, according to the definition of Politecnico di Torino, the "III level". This level of education is in fact restricted to rather few students who, nevertheless for quite some time, work in the research field with the aim of following a University career or facing the Industrial World, with an educational level far higher than the Master's Degree.

III level education in the $\mathrm{PhD}$ courses is based on the two "pillars" of being inside a real research activity and attending specific III level courses that have specific features:

- courses have a short duration (two to six ECTS European Credit Transfer and Accumulation System);

- courses are chosen by students;

- every PhD student is required to acquire 45 ECTS during the three years of the doctoral course;

- the number of students in each course is generally low (10 to 30 );

- courses are not institutional but proposed by a Professor who will be the teacher. Moreover, the Professor may introduce experts, both academic and industrial, who are in most cases foreign;

- courses are proposed in the ambit of a $\mathrm{PhD}$ Course but other students of other PhD Courses can attend them as well.

It is clear that the focus on a specific set of problems makes the courses extremely interesting, even if they can last only a few terms. It is the case for a III level course developed by the Authors to solve a particularly necessary need, which will be introduced in this paper.

\section{Third level education in Aeronautical Engineering at Politecnico di Torino}

Aerospace Engineering is certainly one of the "cutting edge" topics at Politecnico di Torino, thanks to a long tradition that, since the beginning of XX Century, has seen a sequence of Great Professors in several branches of Aeronautics and has taken advantage of the remarkable Aerospace Industry in Turin. Currently, students there are about 150 First Level students and about 120 Second students attending Aerospace Engineering Courses annualy. Both level courses in Aerospace Engineering have been among the very firsts to be certified by EURACE (since 2011) and they currently comply with the National Quality Certification, imposed by the Italian Government through the ANVUR-Agenzia Nazionale di Valutazione del Sistema Universitario e della Ricerca National Agency for Evaluating the University and Research system).The PhD Aerospace Engineering Course has recently been evaluated positively by the ANVUR as well.

The Research group which the Authors belong to has always been interested in Aircraft Design activities, as they consider it the basis from the educational point of view and, therefore, essential to the University. Such a belief derives at first from the experience of collaboration with Professor G. Gabrielli (Gabrielli 1982), teacher at Politecnico di Torino till the ' 80 s and one of the most important Italian aircraft designers. Following the tradition of Professor Gabrielli, the Research Group has always worked on Aircraft Design (Chiesa 1977; Chiesa, Guerra 1983; Chiesa et al. 2000a, 2000c, 2013; Antona et al. 2009), within the larger ambit of System Engineering. As a consequence, the Group has always attended both the EWADE meetings, since the very first year (Chiesa et al. 2002, 2005, 2007a, 2009; Chiesa, Fioriti 2013), and the ones of READ (formerly RRDPAE), (Chiesa et al. 2000b, 2005, 2007b, 2012a, 2016; Fusaro 2014).

With this background the research group has decided to make strong effort to renew the "culture" of Aeronautical Design, in particular by identifying the criticality of Architectural Design Aspects that, considering more qualitative than quantitative definitions, cannot avail the support of strengthened mathematics theories; we are obviously talking about all aspects concerning the aircraft layout definition. It is clear that the same concept of "Aircraft Architecture" has in its nature a global aspect, so the carelessness of this aspect probably requires to leave aside the "aircraft global vision" as, if the Aircraft Design draft is carried on in such a way, the results could be unclear, defined badly and also unreliable. On the other hand, it is obvious that, at the same time, the Aircraft Architectural Definition must proceed with the numerical definition of quantitative parameters 
(for which many efficient algorithms exist, e.g. the one used by the research group (Fioriti 2014)); such a definition must not be left aside nor thrown together.

One of the issue at hand is how to educate young engineers on the Architectural definition of a new aircraft, simultaneously with the Preliminary Design development. The problem is not an easy one to solve, because of the lack of mathematics algorithms (and it cannot be different). Aimed at the solution of this problem, a III level course was set up about a year ago according to the strategies illustrated in the following Section 3.

\section{Basic concepts for aircraft architecture education}

While setting up the course, some preliminary assumptions were made; first of all, due to the extreme innovation and criticality of this topic, at least for the first edition, a reduced amount of hours (ten hours, considered as 2 ECTS) has been settled; on this basis the proposal for the course was made, as shown in Figure 1, which at first was presented to the PhD School of Politecnico di Torino, which approved it. After the approval, the Course Design activity began; it was previewed for the month of June/July, then delayed to September 2014. Such a project brought to define the following sequence of initial topics:

- exemplification, starting from a generic product, of the architectonic aspects (or its layout) compared and integrated with the "quantitative" aspects, which are its main numerically defined characteristics;

- description of the architectural characteristics of an aircraft (example in Fig. 2);

- definition of possible approach modalities in the ambit of a "Conceptual Design" process (Fig. 3);

SCHEDA INFORMATIVA CORSI DI III LIVELLO

(Anno di attivazione 2014)

\begin{tabular}{|c|c|c|c|c|c|c|c|c|c|c|c|c|}
\hline \multicolumn{13}{|c|}{ DOTTORATO DI RICERCA IN INGEGNERIA AEROSPAZIALE } \\
\hline \multicolumn{2}{|c|}{$\begin{array}{l}\text { Titolo del corso in } \\
\text { italiano }\end{array}$} & \multicolumn{11}{|c|}{ ASPETTI TECNICI DELL'EVOLUZIONE DEI VELIVOLI E DELLA LORO ARCHITETTURA } \\
\hline \multicolumn{2}{|c|}{$\begin{array}{l}\text { Titolo del corso in } \\
\text { inglese }\end{array}$} & \multicolumn{11}{|c|}{ TECHINICAL ASPECT OF EVOLUTION OF AIRCRAFT AND THEIR LAY-OUT } \\
\hline \multicolumn{13}{|c|}{$\begin{array}{l}\text { Docente del Politecnico } \\
\text { Docente esterno al Politecnico }\end{array}$} \\
\hline \multirow[t]{6}{*}{ Docente/i: } & \multicolumn{3}{|c|}{ Cognome e Nome } & \multicolumn{2}{|c|}{ Matricola } & \multicolumn{3}{|c|}{$\begin{array}{l}\text { Ore di didattica } \\
\text { frontale }\end{array}$} & \multicolumn{4}{|c|}{ Dipartimento } \\
\hline & \multicolumn{3}{|c|}{ CHIESA SERGIO } & & 0248 & \multicolumn{3}{|c|}{10} & \multicolumn{4}{|c|}{ DIMEAS } \\
\hline & & & & & & & & & & & & \\
\hline & & & & & & & & & & & & \\
\hline & & & & & & & & & & & & \\
\hline & & & & & & & & & & & & \\
\hline \multicolumn{13}{|c|}{$\begin{array}{l}\text { Programma del corso: (in italiano e in inglese) } \\
\text { The main target of the course is to explain to the students that the aircraft architecture is entirely imposed by technical reasons } \\
\text { and then strictly linked to the role, the required performances, the adopted technologies and the engine type. A very good way } \\
\text { of introduce this idea is to critically analyze aircraft evolution (considering fighters, bombers, transport aircraft and executives) } \\
\text { since the beginning of the last century to the present and the future. In addition to that, it will be shown how, in many cases, } \\
\text { architectural characteristics are influenced by the adaptations or modifications of previous models, as it happens also in other } \\
\text { products. Another target is to explain how aircraft evolution is linked to the continuous development of the disciplines that are } \\
\text { its fundamentals. }\end{array}$} \\
\hline \multicolumn{13}{|c|}{ Barrare se si tratta di “insegnamento libero" } \\
\hline \multicolumn{2}{|c|}{\begin{tabular}{l|l} 
Durata del & \\
corso: &
\end{tabular}} & \multicolumn{11}{|l|}{ ore 10} \\
\hline $\begin{array}{l}\text { Periodo } \\
\text { dell'anno: }\end{array}$ & GEN & FEB & MAR & APR & MAG & $\underline{\text { GIU }}$ & $\underline{\text { LUG }}$ & AGO & $\underline{\text { SET }}$ & OTT & NOV & DIC \\
\hline \multicolumn{13}{|c|}{\begin{tabular}{l|l}
$\begin{array}{l}\text { Dottorato } \\
\text { principalmente interessato: }\end{array}$ & Ingegneria Aerospaziale \\
\end{tabular}} \\
\hline \multicolumn{4}{|c|}{$\begin{array}{l}\text { Altri Dottorati potenzialmente } \\
\text { interessati: }\end{array}$} & $\begin{array}{l}\text { gneria } \\
\text { tione } / \mathrm{F} \\
\text { egneria } \\
\text { egneria } \\
\end{array}$ & $\begin{array}{l}\text { Meccanic } \\
\text { oduzione } \\
\text { Elettronic } \\
\text { Energetic }\end{array}$ & Design & & & & & & \\
\hline
\end{tabular}

Fig. 1. The form for the proposal of a III level course 


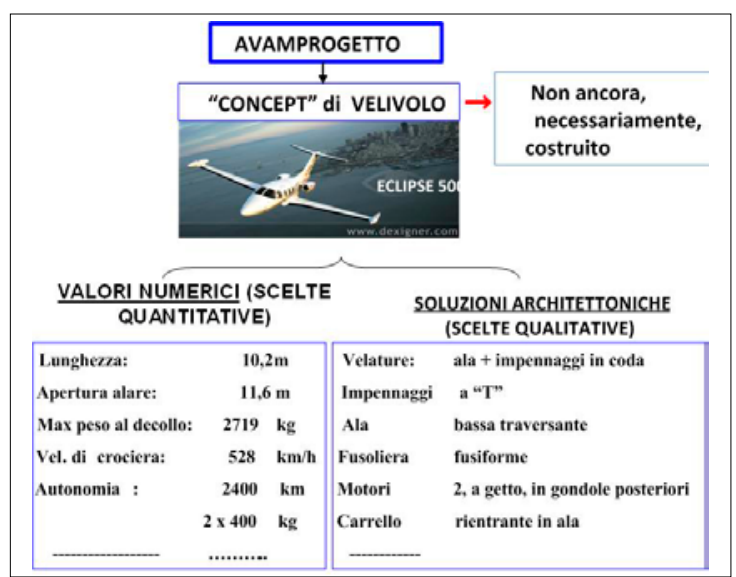

Fig. 2. Architectural characteristics of an aircraft

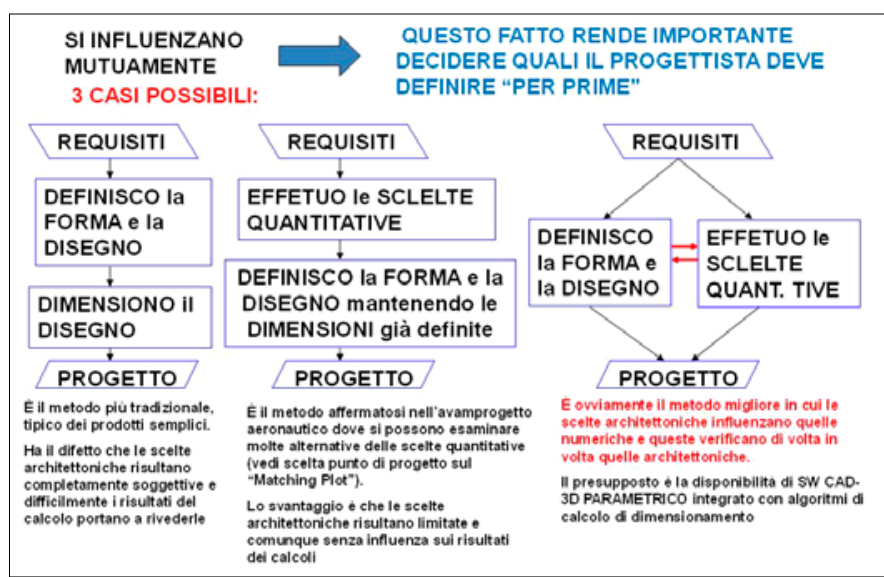

Fig. 3. Approach modalities to the architectural definition in C.D.
- confirmation of the importance of the aircraft architectural definition activity, for the definition level that leads to a "Conceptual Design".

It is also underlined how "Aircraft Design and Layout definition" is now considered one of the activities of the aeronautics Technical Definition, due to a new online advertisement by the Gulfstream Aerospace Corporation for "Research for Human resources" shown.

After the introductive part (necessary to understand what "Airplane Architecture" is and how it can be integrated in the phase of Conceptual Design) the planning of the course found the most difficult conceptual point. How to educate a young engineer in Airplane Architecture activities? On this point the brainstorming among the members of the research group was long and complex. As usual, the aim of the task, which is to propose it to the students and get them to apply a special procedure for an initial sketch of any aircraft object in the "Conceptual design " process is immediately clear, but the main problem is how to get across the sensitivity to architectural aspects, by enabling the student at first to foresee alternative choices, then to analyze and compare them. The main need is that acting according to architectural aspect sensitivity students must consider the type of aircraft and, especially, should lead to the possibility of implementing even uncommon (for the studied case) choices. Authors considered the solution of taking into account the historical evolution of

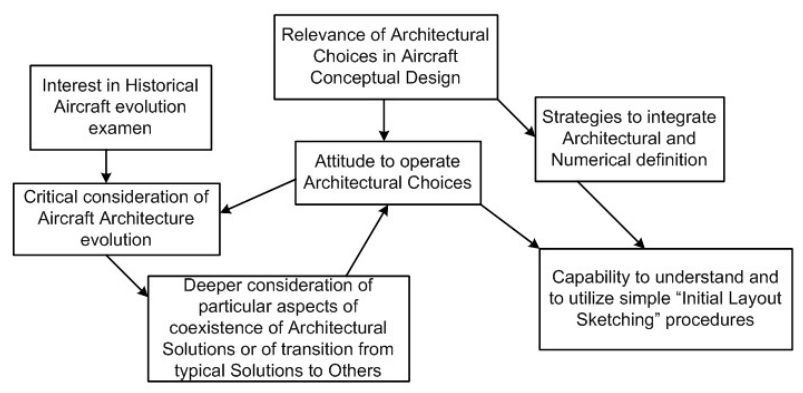

Fig. 4. Brainstorming to define main topics of the course aircraft since the beginning of XX Century till now to be acceptable, observing in a critical way how new architectural solutions stood out due to the technological improvement and how, in a certain technological context for several aircraft generations, the coexistence of different architectural solutions has been possible, with the constant search for optimal solution. The conclusions of the brainstorming process that lead to define this second and, quantitatively more relevant part of the course, are summarized in Figure 4.

\section{Organization of the course}

First of all, once the main topics of the course have been defined, before proceeding to the detailed plan of the course, we arranged for the basic organization step of spreading such topics over the available 10 didactic hours which, due to a commitment to procedure, we were obliged to define previously (Fig. 1). In this basic step, we proceeded with allocating the following course didactical hours for the different topics as follows:

- relevance of architectural choices and strategies to integrate architectural and numerical definition 1.5 hours;

- critical consideration of Aircraft Architecture evolution 4.5 hours;

- presentation and application of "Initial Layout Sketching" procedures $\quad 3.0$ hours;

- final assessment $\quad 1.0$ hour.

Two things are notable:

1. The "final assessment" is required to meet regulations that govern the courses at Politecnico di Torino, as the acquirement of a certain "number of credits", obtained by passing the "final test" of a number of III level courses, is necessary to achieve a PhD. In the present case, in spite of the scarce number of hours on tap for the course, the final assessment was immediately seen, from the beginning, as a necessary way to verify the real possibility of the course of increasing the stu- 


\begin{tabular}{|c|c|c|c|}
\hline & \multicolumn{3}{|c|}{ INCONTRI - LESSONS } \\
\hline & 1 & 2 & 3 \\
\hline Hour 1 & $\begin{array}{l}\text { Relevance of } \\
\text { Architectural } \\
\text { Choices and } \\
\text { Strategies to } \\
\text { integrate } \\
\text { Architectural and } \\
\text { Numerical definition }\end{array}$ & $\begin{array}{c}\text { Critical } \\
\text { consideration of } \\
\text { Aircraft Architecture } \\
\text { evolution }\end{array}$ & $\begin{array}{l}\text { Presentation and } \\
\text { application of "Initial }\end{array}$ \\
\hline Hour 3 & $\begin{array}{l}\text { Critical consideration } \\
\text { of Aircraft } \\
\text { Architecture } \\
\text { evolution }\end{array}$ & $\begin{array}{c}\text { Critical } \\
\text { consideration of } \\
\begin{array}{c}\text { Aircraft Architecture } \\
\text { evolution }\end{array}\end{array}$ & procedures \\
\hline Hour 4 & & & $\begin{array}{c}\text { Final } \\
\text { Assessment }\end{array}$ \\
\hline
\end{tabular}

Fig. 5. Course organization

dents' knowledge and ability. Furthermore, the "vis a vis" discussion with student is considered extremely useful to get suggestions about possible improvements for future editions.

2. The time available, in particular the time for aircraft evolution critical consideration, seemed too short; the solution found was to consider only the "Fighters" evolution, as this category is the one that includes, from the airplanes' architectural point of view, the greatest number of solutions and, consequently, useful sparks.

After the allocation of the time available, the definition of hours in a determined number of meetings was planned, after a prior decision about the duration of the course which must not take more than one week, with the aim of avoiding too long a break between the lessons, which may result in a decrease of students' attention. The following Figure 5 shows the final organization of the course.

It is possible to see that three lessons are planned, two lessons of three hours each and a last comprehensive of a "final assessment" of four hours. The length of three hours (with a break after an hour and a half) seems to be

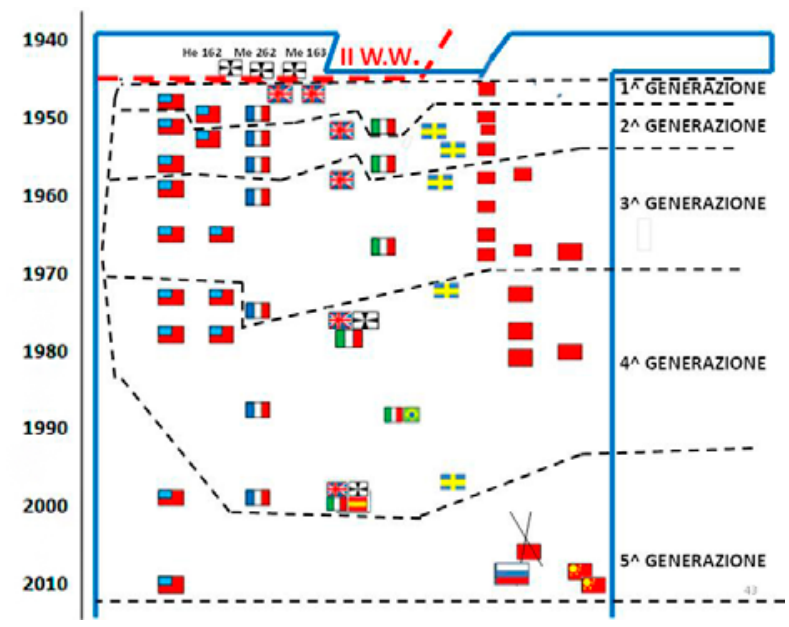

Fig. 6. Jet fighters in the context "Time-Country" a good compromise between the opposite necessities of having lessons either too short (with a risk of having a reduced effect among the many other daily tasks) or too long (with a risk of having reduced attention). The break of the three-hour lessons into two of one hour and a half each is obviously functional with regard to the previously discussed allocation of topic hours. In more detail, the first half of the first lesson will consist of the presentation of the course by introducing the preliminary topics which will be treated in point 2 , with a description of how the course is organized with the aim of getting the desired results. The second part of the first lesson and the entire second lesson, for a total of four and a half hours, will show the critical consideration of aircraft evolution, which is the core of the course, as it should raise the interest of students and give them the sensitivity to aircraft architecture. In consequence of such a realization, in the third lesson students should easily understand and employ simple "initial layout sketching" procedures, with sufficient time for the final assessment. A short in-depth analysis on the aircraft evolution critical consideration and the "initial layout sketching" procedures are going to be presented, as these aspects are the real core of the course.

\subsection{Aircraft evolution critical consideration}

As already mentioned, the goal of this part of the course is to illustrate aircraft architectures by analyzing them and explaining the relative motivations; after examining their variations, corresponding changes in technology, the students will learn how to associate the architectural choices with well-defined technical reasons. As to "motivational" aspects, the idea of raising interest in the Aeronautical field, several aircraft will be considered due to the time context when they were designed/utilized, as well as the country of origin, as shown in Figure 6. For each examined aircraft a pictorial image (that will give an exact, even if preliminary, idea of the architecture) will be shown and they will then be divided into groups of different time periods as good examples of alternative solutions, as shown in Figure 7.

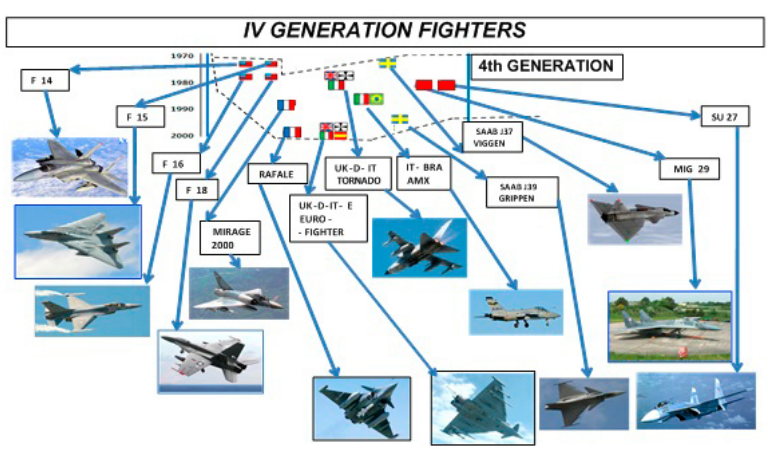

Fig. 7. The $4^{\text {th }}$ generation jet fighters; architecture comparison 


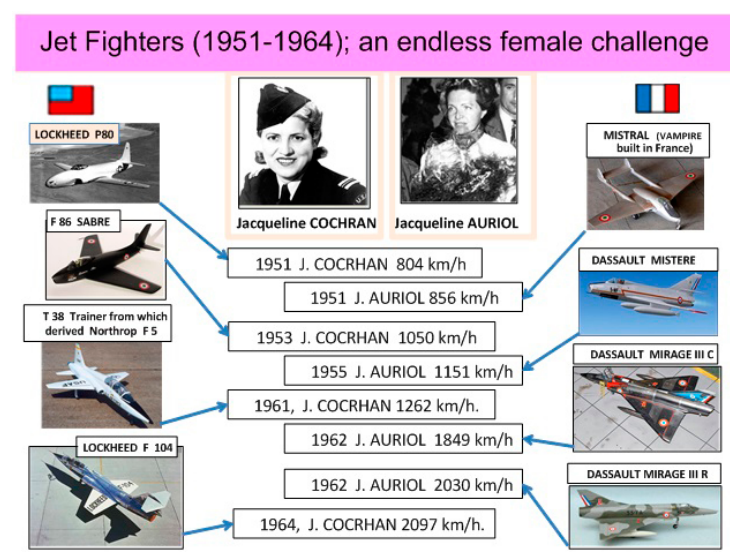

Fig. 8. Fighter speed evolution - Female Competition

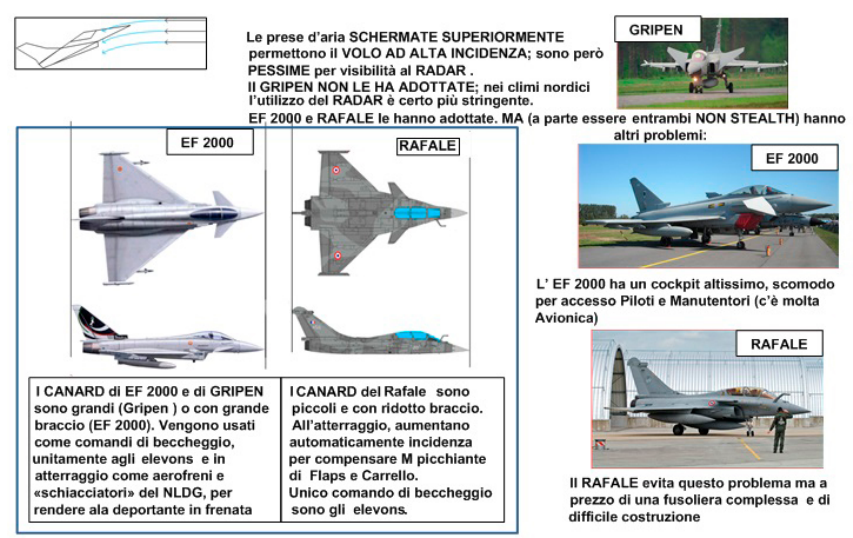

Fig. 9. Analysis of dissimilarities of EF 2000, Rafale, and Gripen
It is notable that in the ambit of didactical material students will be supplied with the technical files of main data for each examined aircraft. As already mentioned, with the aim of closely involving students in the topic, the discourse will also include anecdotes, such as the story of the competition for the "female" speed record, which exemplifies well the variation, also architectural, of fighters from the beginning of the ' 50 s to mid' 60 s, marked by the change from subsonic speed to Mach 2 (see Fig. 8).

Other more technical analyses clarifications will be introduced when appropriate; an example is shown in Figure 9, it concerns the three contemporary European fighters, (Eurofighter EF2000, Dassault "Rafale" and Saab JAS 39 "Gripen"). At first sight, these aircraft appear similar in architecture because they are all equipped with the "Delta-Canard", but a deeper analysis shows that they have completely different solutions, from the architectural point of view as well.

\subsection{Initial Layout sketching procedures}

As to these procedures, it has already been said that they need to be simplified because of the reduced education time, as the especially simple application considered in the course will not be included in a real Conceptual Design process and then the numerical data achievement will be simulated. A preliminary idea of the "Initial Layout Sketching" procedure (presented in detail in

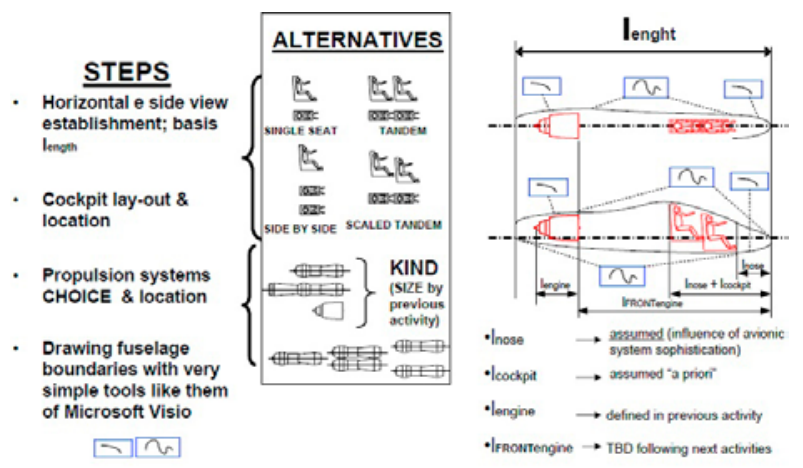

Fig. 10. Procedure's steps and pre-defined figures
Chiesa et al. (2005)) results from the consideration that such a procedure, as shown in Figure 10, will oblige to set the fuselage side and top view, on the basis of its length (value given by Conceptual Design). Default figures for crew members and several types of engines will be given to the students (who will obviously coordinate the scales). The possibility of positioning the cockpit, defining the nose dimensions, obviously imposed by the chosen avionic typology will be allowed; the engines will be positioned as well, but not definitely. The next step, see Figure 11, shows the introduction of the wing top view (definition from the Conceptual Design). The positioning will be made after the definition of the main structural members of the wing, after considering the need of the CoG to be near the aerodynamic centre and in front of the main landing gear; the process completion is shown in Figure 12, as well as the wing height positioning, while trying to obtain the most logical structural layout solution (for example the main landing gear and engines are attached to the same rib joint to the rear wing spar).

The structural layout must also allow an adequate path of air induction ducts to the engine/s. In this phase the aircraft's sketch can be completed with a tail and control surfaces draft, thus reaching a three (or only two) view sketch, which well identifies the aircraft's concept (see Fig. 12 again).

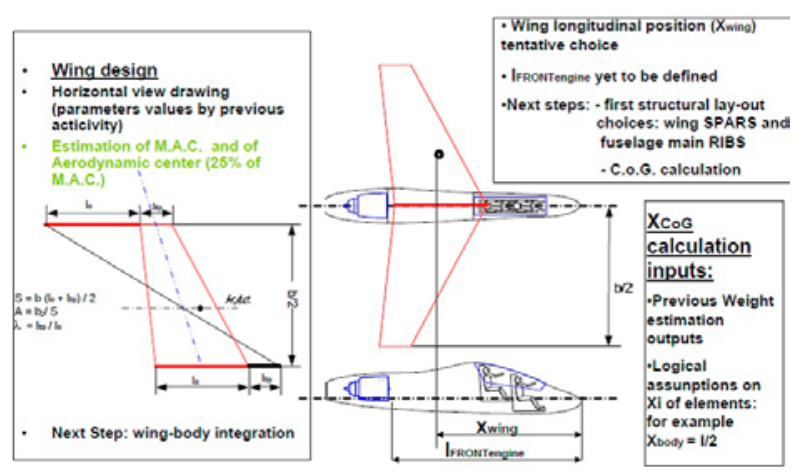

Fig. 11. Wing platform and fuselage sketch (men, engines) 


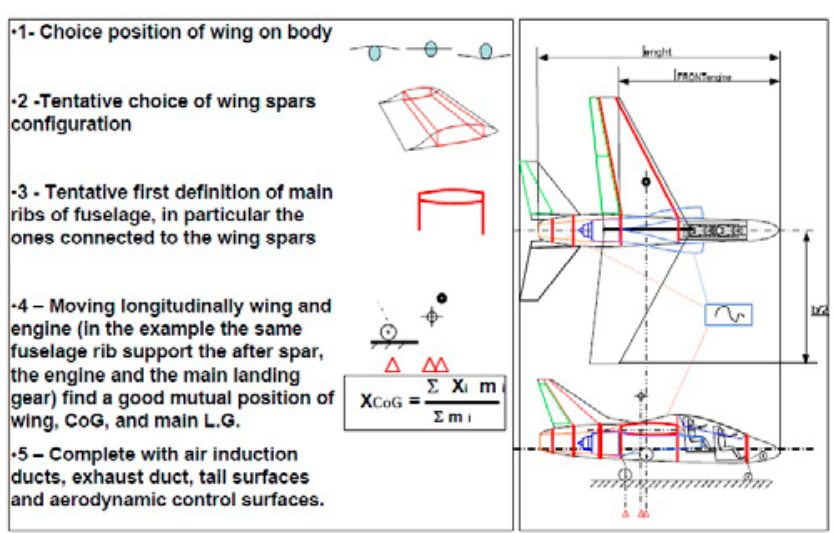

Fig. 12. Wing/fuselage assembly, rib and spars definition, LNDG integration

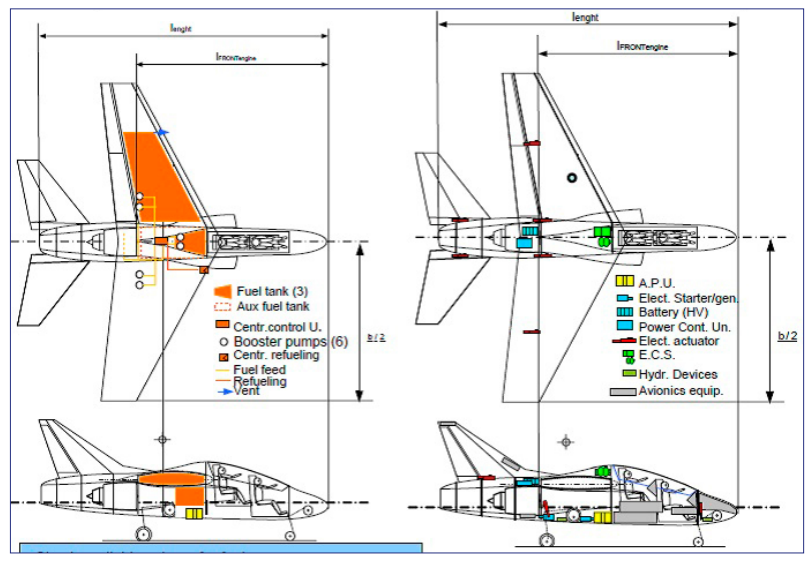

Fig. 14. System installation preliminary study

Figure 13 shows that it is necessary, for an effective Conceptual Design, to have the definition, obviously at a preliminary level, of the main on-board Systems; mainly because of the great relevance of on-board systems definition for a conceptual design, see (Chiesa et al. 2012b; Fusaro et al. 2016; Prakasha et al. 2016). Figure 14 shows that, after defining the several on-board system layouts, it is possible to preview (and this is one of the most typical Aircraft Architecture operations) a preliminary installation of the systems in the aircraft. During the preliminary installation of systems, many checks, like the CoG recalculation and, for example, the verification of fuel tank capacity, have to be performed.

The physical placement of the main on-board systems' elements bring us to define the Accessibility hypothesis, which is the envisioning of removable panels for maintenance needs, as shown in Figure 15; with the choice about the disassembly of structural elements (previously defined) a complete definition of the structural layout is obtained. This allows, as shown in the same Figure 15, even hypothesizing on the possible aircraft assembly flow, hence achieving a considerable level of Concept definition.

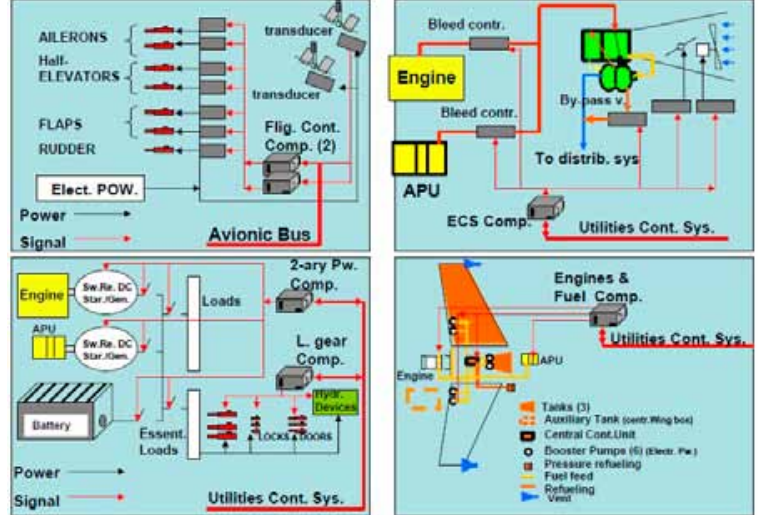

Fig. 13. Preliminary (layout level) systems definition

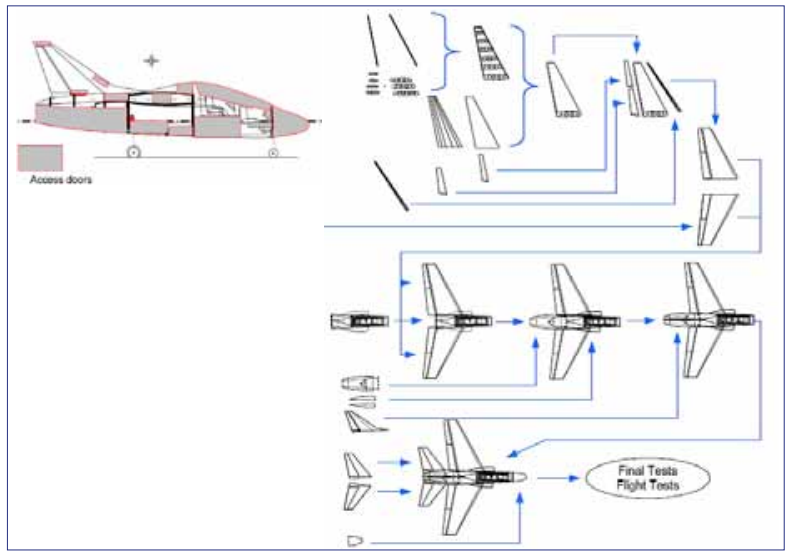

Fig. 15. Accessibility studies and first hypothesis about assembly flow

As consequence, even if restricted to an extremely short course, we have the belief that the effect on students greatly involved in Aircraft Architecture can be important.

\section{Conclusions}

A course to improve the knowledge and the abilities, in the field of Aircraft Architectural definition, of high level students in Aeronautics Engineering has been studied and defined. The main strategic choice has been to illustrate aircraft architecture to students, by describing and analyzing aircraft evolution, accompanying it with examples from the first years of the XX Century to the present. The interest of Aeronautics Engineering students that would be generated by the study of several aircraft during their historical evolution is considered a very effective promotional factor.

The definition of the course process is described, underlining the organization, list of topics and time allocation.

Upon completion of the course, the students will have the possibility of trying to perform simple architectural definitions by a simplified but complete "Layout 
Sketching Procedure", with the aim of giving, even with a very few hours available, a complete vision of an airplane's architectural definition, useful at the Conceptual Design level.

\section{Disclosure statement}

The Authors declare to have no competing financial, professional or personal interests from other parties.

\section{References}

Antona, E.; Chiesa, S.; Corpino, S., et al. 2009. L’avamprogetto dei Velivoli, Atti dell'Accademia delle Scienze di Torino.

Chiesa, S. 1977. Un problema di configurazione: scelta del posizionamento dei propulsori per velivoli civili a getto, Pubblicazione dell'Istituto di Progetto di Aeromobili, Torino.

Chiesa, S.; Guerra, G. 1983. Progetto concettuale di velivoli da trasporto, Ingegneria $7(8)$.

Chiesa, S.; Camatti, D.; Corpino, S., et al. 2000c. Hypothesis about cost-effective unmanned offensive airplane vehicles, Aircraft Design 3(3). Oxford: Elsevier Science Ltd.

Chiesa, S.; Borello, L.; Maggiore, P. 2000a. An academic experience about aircraft design: affordable advanced jet trainer, in the $22^{\text {nd }}$ ICAS Congress, 27 August - 1 September 2000, Harrogate, UK.

Chiesa; S.; Fioriti, M.; Fusaro, R. 2013. Hybrid configuration advanced A.P.U. concept for future TurboProp, in the XXII Congress of AIDAA-Associazione Italiana di Aeronautica e Astronautica, 9-12 September 2013, Naples, Italy.

Chiesa, S.; Corpino, S.; Viola, N. 2002. Global change of configuration at conceptual design level: a particular way for the evolution and the optimisation of the design, in the 5 th European Workshop on Aircraft Design Education, 2-4 June 2002, Linkoping, Sweden.

Chiesa, S.; Corpino, S.; Viola, N. 2005. Aircraft design for systems engineers education at Politecnico di Torino, in EWADE, 2005, Toulouse, France.

Chiesa, S.; Corpino, S.; Viola, N., et al. 2007a. Advanced ultralight and UAV synergic family studied at Politecnico di Torino, in EWADE, 29 May - 02 June 2007, Samara, Russia.

Chiesa, S.; Viola, N.; Farfaglia, S. 2009. The SAvE Programme; a technical Challenge, an interesting opportunity for education, in EWADE, 13-15 May 2009, Sevilla, Spain.
Chiesa, S.; Fioriti, M. 2013. About feasibility of a $5^{\text {th }}$ generation light fighter aircraft, in the $4^{\text {th }}$ International Congress CEAS, 16-19 September 2013, Linkoping, Sweden.

Chiesa, S.; Camatti, D.; Corpino, S., et al. 2000b. Affordable technological demonstrator for hypersonic flight, in the 4 th International Seminar on RRDPAE, 2000, Warsaw, Poland.

Chiesa S.; Corpino, S. ; Cernusco, A., et al. 2005. Mini-UAV remote control: a case study at Politecnico di Torino, Aviation 8(3): 31-40.

Chiesa, S.; Corpino, S.; Fioriti, M., et al. 2007b. Virtuals and flying models for aircraft evelopment, Aviation 11: 3-12.

Chiesa, S.; Di Meo, G. A.; Fioriti, M., et al. 2012a. ASTRIDAircraft on board aystem aizing and trade off analysis in initial design, in Proceeding of research and education in aircraft design (READ) 17-19 October 2012, Brno, Czech Republic.

Chiesa, S.; Fioriti, M.; Fusaro, R. 2016. Possible hybrid propulsion configuration for transport jet aircraft, Aviation 20(3): 145-154. https://doi.org/10.3846/16487788.2016.1200849

Chiesa, S.; Fioriti, M.; Viola, N. 2012b. Methodology for an integrated definition of a System and its Subsystems: the case-study of an Airplane and its Subsystems, in Systems Engineering - Practice and Theory. InTech. https://doi.org/10.5772/34453

Fioriti, M. 2014. Adaptable conceptual aircraft design advanced model, Aircraft and Spacecraft Science 1: 43-67. https://doi.org/10.12989/aas.2014.1.1.043

Fusaro, R. 2016. The advantages of a hybrid piston prop aircraft, Aviation 20(2): 85-97. https://doi.org/10.3846/16487788.2016.1198093

Fusaro, R.; Ferretto, D.; Viola, N. 2016. Model-Based Object-Oriented systems engineering methodology for the conceptual design of a hypersonic transportation system, in ISSE 2016 - 2016 International Symposium on Systems Engineering, 3-5 October 2016, IEEE. Art. no. 7753175. https://doi.org/10.1109/SysEng.2016.7753175

Gabrielli, G. 1982. Lezioni sulla Scienza del Progetto degli Aeromobili. Levrotto, Bella, Torino.

Prakasha, P. S.; Ciampa, P. D.; Boggero, L.; Fioriti, M. 2016. Assessment of airframe-subsystems synergy on overall aircraft performance in a collaborative design environment, in 17th AIAA/ISSMO Multidisciplinary Analysis and Optimization Conference, 13-17 June 2016, Washington, United States. $16 \mathrm{p}$. 